\title{
TODOS NÓS SEMOS DE FRONTERA: IDEOLOGIAS LINGUÍSTICAS E ACONSTRUÇÃO DE UMA PEDAGOGIA TRANSLÍNGUE*
}

\author{
Adriana Carvalho Lopes* \\ Universidade Federal Rural do Rio de Janeiro \\ Instituto Multidisciplinar \\ Departamento de Educação \\ Nova Iguaçu, RJ, Brasil \\ Daniel do Nascimento e Silva ${ }^{* *}$ \\ Universidade Federal de Santa Catarina \\ Centro de Comunicação e Expressão \\ Departamento de Língua e Literatura Vernáculas \\ Florianópolis, SC, Brasil
}

\begin{abstract}
Resumo: Este artigo busca deslocar o debate sobre o ensino de língua portuguesa do campo da natureza e trazê-lo para o campo da política. Para isso, ele propõe que problematizar ideologias linguísticas, entendidas como racionalizações leigas e especializadas sobre a forma e a função da linguagem, equivale a politizar o ensino, na medida em que essas ideologias são investidas de interesses políticos dos grupos que as sustentam. Empiricamente, o artigo questiona as ideologias monolíngues que embasam os Parâmetros Curriculares Nacionais e outros discursos sobre a nação, contrastando-as com a produção poética e as racionalizações de Fabian Severo, poeta uruguaio e professor que escreve em portunhol. O texto explora, ainda, alinhamentos e fricções entre ideologias linguísticas entre estudantes que participaram de uma proposta translíngue de ensino de língua materna.
\end{abstract}

Palavras-chave: Pedagogia translíngue. Portunhol. Ideologias linguísticas.

\footnotetext{
* Pesquisa aprovada no Comitê de Pesquisa CCE/UFSC, Proc. Nr. 201703314.

** Professora Adjunta do Departamento de Educação e Sociedade do Instituto Multidisciplinar IM/ UFRRJ. Professora Colaboradora do Programa de Pós-graduação Interdisciplinar em Linguística Aplicada da Universidade Federal do Rio de Janeiro - UFRJ. ORCID: 〈https://orcid.org/0000-0002-6068-8308>. Email: adrianaclopes14@gmail.com.

**** Professor Adjunto do Departamento de Língua e Literatura Vernáculas. Professor Colaborador do Programa de Pós-graduação Interdisciplinar em Linguística Aplicada da Universidade Federal do Rio de Janeiro (UFRJ). ORCID: < https://orcid.org/0000-0002-6098-5185>. E-mail: dnsfortal@ gmail.com.
} 
O ensino de língua portuguesa no Brasil - também denominado ensino de língua materna - sempre foi imaginado como uma atividade em que os/as aprendizes são ensinados a obedecer a um padrão, para que possam assim tornar-se sujeitos viáveis. Antes mesmo de o país tornar-se república, em 23 de agosto de 1871, Pedro II, o último imperador do Brasil, instituiu o cargo de Professor de Português. Relatos de catequizadores e de reis alertavam para a necessidade de ensinar a língua do príncipe para os povos colonizados como uma forma de criar vassalos úteis à Coroa (BUNZEN, 2011).

Da Monarquia à República, apesar da extrema diversidade cultural e linguística que sempre caracterizou o território brasileiro, os governos sempre reforçaram a construção de uma imaginação ${ }^{1}$ de um país homogêneo e monolíngue. Segundo Soares (2002), de 1820 a 1920, fazia parte da política linguística do Brasil valorizar e impor a língua da coroa, pois esta era entendida como meio de civilizar os povos bárbaros e, ao mesmo tempo, banir as línguas dos povos indígenas, das populações vindas de países africanos e a língua geral, o nheengatu - esta última considerada uma invenção abominável e diabólica. Não foi por acaso que, nesse período, foi instituído o ensino de uma "língua que postulava uma modalidade única do português - com uma gramática única e uma 'luta' acirrada contra as variações, até de pronúncia' (p.162).

No período republicano, Signorini (2004) aponta que a imaginação de homogeneidade linguística no ensino tem invocado o ideal iluminista de "esclarecer o ignorante em matéria de língua", supostamente permitindo o acesso aos padrões de prestígio para que todos possam participar de bens comuns. Essa idealização iluminista, no entanto, desconsidera as "heterogeneidades constitutivas da língua falada pelo conjunto dos falantes" do português, terminando por contribuir com a exclusão de grupos periféricos (p. 90). Assim, historicamente, os sujeitos viáveis produzidos pelas imaginações sobre o que é ensinar língua portuguesa no Brasil têm sido socializados, de forma geral, a partir da ideologia linguística de que há uma língua nacional única, fixa e homogênea (CAVALCANTI; MAHER, 2018; SIGNORINI, 2002), recurso adequado para a formação de cidadãos também adequados (SIGNORINI, 2004).

Esse breve panorama histórico nos lembra que a constituição desse objeto de ensino sempre esteve relacionada com o movimento colonial e suas aspirações políticas. Entendendo que, geralmente, a natureza política de ensinar língua portuguesa no Brasil tende a ser uma questão esvaziada (ou ausente) nas propostas, problematizações e práticas de ensino, pretendemos, neste artigo, promover um debate político sobre o ensino de língua portuguesa, focalizando as ideologias linguísticas - "quaisquer conjuntos de crenças sobre a língua articulados pelos usuários como uma racionalização ou justificação de estrutura e uso linguístico percebidos" (SILVERSTEIN, 1979, p. 193) - que informaram o diálogo, o dissenso e o conflito numa experiência de ensino translíngue

\footnotetext{
1 Inspirada pela proposta da antropologia linguística (SILVERSTEIN, 1979) de entender ideologias linguísticas como uma camada de crenças sobre línguas e seu funcionamento, parte da linguística aplicada no Brasil (MOITA LOPES, 2013; SILVA, 2015) tem teorizado ideologias linguísticas em termos de distintas "imaginações" sobre a linguagem.
} 
num contexto universitário de ensino de língua materna. Conforme discutiremos abaixo, nossa posição é que problematizar ideologias linguísticas no ensino equivale a politizar o debate, pois ideologias linguísticas são "atravessadas por questões políticas e morais presentes no campo sociolinguístico particular e são sujeitas aos interesses da posição social dos portadores dessas ideologias" (IRVINE; GAL, 2000, p. 35).

A priori, convém problematizar o próprio nome do objeto de ensino, 'língua materna', porque ele carrega conotações de um dos termos da dicotomia natureza/cultura. 'Materna', a língua que aprendemos ao nascer, figura como um fato da natureza; metaforicamente, as crianças de uma nação nascem de uma grande mãe biológica, a língua natural que irão adquirir e da qual serão seus falantes nativos. Aqui, o elemento 'natureza' do par natureza/cultura associa-se à ideologia linguística modernista que faz coincidir "um povo, uma nação, uma língua" num projeto monolíngue que não é politicamente neutro.

Assim, historicamente, a natureza tem sido subjugada à cultura nessa divisão hierárquica de termos. Tomando, por exemplo, os modos como o dicionário Houaiss (2001) define 'homem' e 'mulher', veremos que o primeiro é definido nos termos do universal e da cultura, já a segunda é situada no plano da natureza. Enquanto no dicionário o homem é posicionado nos termos da cultura - ícone do ser humano racional, dotado de capacidade de abstração -, a mulher é continuamente definida nos termos da natureza ("indivíduo do sexo feminino considerado a partir de suas características biológicas"), sendo "sua vida genital percebida como [própria] essência".

Mesmo quando referido nos termos da natureza, o homem tem detalhes naturais mínimos ou inexistentes. Ancorada em outras hierarquias, a falta de balanço entre um conjunto de definições e o outro é fundada na naturalização da mulher. Nos termos da filosofia política de Hannah Arendt (1991), naturalizar um conceito significa instrumentalizá-lo, esvaziando-o assim de sua constituição política. Não é à toa que movimentos políticos de grupos minoritarizados, como negros e mulheres, lutam centralmente pela desnaturalização de sua condição: militantes negros, por exemplo, combatem a adjetivação 'de cor', argumentando que a cor (um atributo da natureza) também é um marcador - embora tornado invisível - das pessoas brancas.

Invocamos as inferências acima para argumentar que questionar a naturalização do ensino de língua materna é uma forma de deslocá-lo do campo da natureza e trazê-lo para o campo da política. Esta reflexão está articulada da seguinte forma. A seção 2 discute a ideologia linguística monolíngue dos Parâmetros Curriculares Nacionais. Como resposta a essa projeção de monolinguismo num país sociolinguisticamente complexo, a seção 3 apresenta os princípios de uma "pedagogia translíngue", entendida como proposta de ensino aberta à diferença nos modos de usar a língua. A seção 4 especifica o modo como politizamos a diversidade linguística num contexto particular de ensino, por meio de uma ação translíngue implementada por Adriana Lopes mas planejada e discutida com Daniel Silva. Como o estímulo a disposições translíngues em sala adveio em parte de nossa leitura e diálogo com Fabian Severo, poeta e professor nascido em Artigas, na fronteira Uruguai-Brasil, a seção 5 aborda uma entrevista com ele sobre sua literatura em portunhol e seu questionamento de ideologias linguísticas modernistas. A seção 6 analisa uma roda de conversa sobre língua-padrão, práticas translíngues e a poesia de Severo. 


\section{OS PCNS E O SUPOSTO MONOLINGUISMO BRASILEIRO}

Esta seção discute o ideal monolíngue de nação projetado pelos Parâmetros Curriculares Nacionais (doravante, PCNs), diretrizes oficiais de ensino publicadas pelo governo federal em 1996. A um só tempo criticados (SUASSUNA, 1998) e influenciados pelo movimento que ficou conhecido como virada pragmática no ensino de língua portuguesa (GERALDI, 2002), os PCNs incorporaram uma crítica aos modelos de ensino estruturalistas, enfatizando - em linha com Geraldi - que compreender a língua como um conteúdo referencial oculta o poder social, ideológico e transformador da palavra. No entanto, a exemplo da virada pragmática, os PCNs deixaram de lado um debate mais profundo sobre ideologias linguísticas, enfocando ao contrário em "concepções de linguagem". Além disso, os PCNs reforçaram a imaginação de um país homogêneo e monolíngue.

Já que um documento oficial, como qualquer texto, é um produto de seu tempo, invocaremos o panorama histórico que antecedeu elaboração dos PCNs. Com o fim da ditadura militar, o país viveu, no início da década de 1980, um forte movimento pela democratização da sociedade e do acesso à escola. Mesmo sendo locais de reprodução de saberes disciplinares, as escolas passaram a ser encaradas como possibilidade de transformação social (FREITAS, 2002). A Pedagogia do Oprimido, escrita por Paulo Freire durante seu exílio político, também teve grande impacto, possibilitando a construção de novos olhares para a formação docente. Esta deixou de ser pensada como transmissão de saberes descontextualizados e elitistas e passou a ser encarada como prática de formação de sujeitos críticos.

Nos cursos de Letras, a preocupação com ensino começou a impor-se aos seus currículos. Segundo Ilari (1997, p. 2), até então, as faculdades de letras desenvolviam "programas muito distantes da realidade: a formação que eles proporcionavam era histórico-filológica, centrada em disciplinas como Filologia Portuguesa, Literatura Medieval e reforço gramatical." De forma eurocêntrica e iluminista, formavam-se professores como críticos literários conhecedores de grandes obras, que seriam capazes de avaliar e retirar "as carências das classes sob sua regência" (p. 6). Os currículos das faculdades de letras passaram a ser revisitados devido a sua "ineficiência como centros de formação de professores para o ensino de língua materna" (ILARI, 1997, p. 2). Em resposta a vários questionamentos, uma forte crítica acadêmica ao que passou a ser cunhado como "ensino tradicional" (GERALDI; SILVA; FIAD, 1996) marcou esse período, que acompanhou uma grande ampliação das pesquisas que impactaram o ensino de língua materna. Afastando-se de um paradigma mecanicista e utilitário, essas pesquisas contribuíram para que a língua fosse vista como "enunciação que inclui as relações da língua com aqueles que a utilizam, com o contexto em que é utilizada, com as condições sociais e históricas de sua utilização" (SOARES, 2002, p. 172). Tal perspectiva promoveu, assim, a chamada virada pragmática na educação em língua materna, fundamentando os documentos oficiais de ensino, em especial os PCNs de língua portuguesa.

Sem deixar de reconhecer o impacto democratizante da virada pragmática construída nesse documento oficial, entendemos que os PCNs, ao lado de outras 
instituições - como a escola, a universidade, as academias literárias, os manuais de redação jornalísticos etc. (ver SIGNORINI, 2002) - cumprem um papel homogeneizador. Esse documento reforça a imaginação de que o Brasil, a despeito de seu multilinguismo, é monolíngue (CAVALCANTI; MAHER, 2018). Argumentamos que a forma de padronização do saber, nos PCNs, se dá sobretudo pela adesão a uma ideologia monoglota de língua (SILVERSTEIN, 1996). Compreendemos com Silverstein (1996, p. 284) que agências unificadoras como os PCNs disseminam ideologias linguísticas que sustentam a "cultura monoglota da língua padrão." Assim, por mais que haja, nas cidades contemporâneas, evidências de um enorme "plurilinguimo societal" (no transporte público, nas escolas, nas mídias sociais etc.), vivemos em estados-nações que tentam continuamente constituir-se como sociedades oficialmente unificadas, formadas por uma Cultura pública uniforme, cujas linhas de demarcação são efetuadas sobretudo por uma língua imaginada, assumida como a língua correta, nacional ou padrão. Milroy (2011) ressalta que a língua-padrão é uma espécie de "métrica" pela qual se classificam não só práticas linguísticas que serão consideradas corretas ou de prestígio, mas também valores e identidades pessoais dos falantes. Assim, um dos elementos dessa ideologia monoglota padrão é que acreditar nela equivale a uma questão de bom senso, afinal o padrão, embora não exista como coisa tangível, é um índice daquilo que é desejável e moralmente bom.

O cenário sociolinguisticamente complexo e multilíngue do Brasil, já problematizado na literatura especializada anteriormente à elaboração dos PCNs (p. ex., BORTONI-RICARDO, 1985; MAHER; CAVALCANTI, 1993), não comparece nos documentos de língua portuguesa. Neles, a diversidade linguística é tratada nos termos do debate sobre variedades linguísticas - consequentemente, as ideologias linguísticas sobre correção ou adequação linguísticas são vistas segundo a lente do "preconceito linguístico". A referência ao bi/multilinguismo só ocorre no documento dedicado aos Temas Transversais - e mesmo esse texto, que trata das diferentes línguas das etnias indígenas e das línguas de populações imigrantes, mede a heterogeneidade linguística brasileira a partir do "papel unificador da Língua Portuguesa":

\footnotetext{
Tratar de bilinguismos e multilinguismos é uma forma de mostrar a riqueza da diversidade que sabe desenvolver-se mantendo elementos comuns e elementos singulares. Será possível trabalhar a importância da língua como fator de identidade para um grupo étnico, tratando da estrutura e do uso das diferentes línguas das etnias indígenas presentes no Brasil, ou da manutenção da língua do país de origem em colônias de imigrantes. Ao mesmo tempo, tratar do papel unificador da Língua Portuguesa é oferecer à criança instrumentos para que entenda fatores determinantes da vida cultural, em termos nacionais. (BRASIL, 1997, p.78, grifo dos autores)
}

O monolinguismo é, assim, a "régua" que mede a capacidade da criança de acesso à "vida cultural, em termos nacionais", isto é, à Cultura. Com Silverstein (1996, p. 287), entendemos que ideologias linguísticas são racionalizações ou justificações que oferecem "modelos metafóricos de interpretação" para uma situação sociolinguística particular. A racionalização dos PCNs de que há uma Língua unificadora (e uma concepção de linguagem única), capazes de agregar toda uma diversidade em nome de um único ideal nacional, é uma operação de naturalização. Ou seja, essa ideologia trata de forma não problematizada a hierarquização de línguas e dialetos no Brasil, escamoteando os processos políticos de produção da desigualdade linguística. A diferença linguística é 
assim vista como um já dado, como algo natural, cabendo à escola apenas pacificar e unificar - "tratar do papel unificador da Língua Portuguesa".

Uma pedagogia translíngue do ensino de língua portuguesa busca deslocar da natureza o problema da desigualdade, movendo-o para a política. Avancemos.

\section{PRINCÍPIOS DE UMA PEDAGOGIA TRANSLÍNGUE}

No contexto norte-americano, Horner et al. (2011) propuseram uma "abordagem translíngue" para o ensino de escrita em inglês. Essa proposta translíngue de ensinar uma língua vista como entidade autônoma e discreta nasce do reconhecimento de que o "uso da língua em nossas salas de aula, nossas comunidades, a nação e o mundo tem sempre sido multilíngue em vez de monolíngue" (p. 303). Influenciados pela proposta, Lee e Jenks (2016, p. 317) resumem que uma abordagem translíngue em contextos vistos como monolíngues é uma forma de cultivar disposições translíngues - "uma abertura geral à pluralidade e à diferença no modo como as pessoas usam a língua".

Uma abordagem translíngue no ensino é orientada para a diferença. Ao passo que abordagens monolíngues tendem a ver a diferença como deficiência, como barreira ou como marca de inferioridade (ver PINTO, 2013), a pedagogia translíngue pergunta: "o que a diferença pode fazer?" (HORNER et al., 2011, p. 303). Em linha com estudos na sociolinguística da globalização que veem línguas e suas funções não como entidades mas como recursos (BLOMMAERT, 2010; CAVALCANTI; MAHER, 2018) ou como potenciais semióticos (FABRÍCIO; BORBA, no prelo), a pedagogia translíngue enxerga a diferença "não como barreira a superar ou problema a resolver, mas como recurso para produzir significado" (HORNER et al., 2011, p. 303, grifo nosso).

Ao contrário de metáforas como a da folha de papel, superfície plana que Saussure emprega para imaginar o signo linguístico, uma pedagogia translíngue imagina línguas e seus signos como caleidoscópios (CÉSAR; CAVALCANTI, 2007, p. 61), como "um conjunto de variáveis, interseções, conflitos, contradições, socialmente constituídos ao longo da trajetória de qualquer falante." Caleidoscópios são instrumentos óticos que permitem a projeção infinita de mosaicos; a sua rotação faz que as imagens projetadas se modifiquem e se recombinem. As figuras múltiplas, recombinantes e em movimento do caleidoscópio são uma metáfora distinta tanto da sincronia quanto da sin-topia saussurianas: para Blommaert (2010), a sincronia saussuriana - "a ideia de que os fenômenos linguísticos podem ser examinados sem que se leve em conta sua situacionalidade temporal e espacial" (p. 196) - é também uma sin-topia, isto é, uma forma de imaginar línguas e falantes como seres imóveis no tempo e no espaço, ignorando-se os "fluxos transculturais, a transidiomaticidade e a desterritorialização" (p. 4) intensificados no atual estado da globalização.

Ao imaginar línguas e seu ensino, a pedagogia translíngue se situa, obviamente, num território simbólico sempre em disputa. A questão aqui não é tratar a diferença, ingenuamente, como algo a ser tolerado ou meramente celebrado - um fato da natureza -, mas reconhecer que os recursos linguísticos são desigualmente distribuídos e que a luta por eles é política. Isto é, a pedagogia translíngue reconhece a naturalização a que a diferença sociolinguística é submetida socialmente e procura deslocar a diferença do campo da natureza para o campo político. 
Foi exatamente a preocupação com a politização do ensino que nos norteou na preparação do curso Ensino de Língua Materna II que Adriana Lopes ministrou em 2017.2 para graduandas/os de Letras-Português e Letras-Espanhol, no Instituto Multidisciplinar da Universidade Federal Rural do Rio de Janeiro (IM/UFRRJ), em Nova Iguaçu, região metropolitana do Rio de Janeiro. Criado em 2005, com o Programa REUNI, o IM possui um corpo discente bastante diferente do público que estudava nas universidades públicas federais, antes do período de sua expansão na primeira década dos anos 2000. Segundo Azevedo (2017), as licenciaturas do IM são formadas, em sua maioria, por mulheres que se autodeclaram negras e são a primeira geração de suas famílias a acessar o ensino superior público.

Buscando dar visibilidade à heterogeneidade cultural e linguística que historicamente foi silenciada e invisibilizada na escolarização brasileira (CAVALCANTI, 1999), utilizamos em nosso trabalho dois métodos fundamentais para as pesquisas em linguística aplicada e em educação: a etnografia e a pesquisa-ação. Numa imaginação etnográfica, em que as práticas linguísticas são entendidas como fenômenos inseridos em atividades humanas complexas e contextualizadas, construímos uma açãointervenção planejada de acordo com as demandas de um grupo específico. Situando-nos no cruzamento dessas perspectivas, buscamos politizar o debate linguístico e construir com o corpo discente imaginações diferentes sobre o que elas e eles chamam de "língua" e que se tornará, futuramente, seu objeto de ensino. O curso foi, assim, uma tentativa de construir com o corpo discente disposições translíngues, entendidas como uma abertura subjetiva e afetiva para habitar fronteiras permeadas por diferentes práticas linguísticas ainda que de forma provisória (porque conscientes do conflito e da desigualdade linguísticos). Com Anzaldúa (1987, p. 19), consideramos que, mais do que física, fronteira é uma categoria simbólica, um território de trocas e de fluxos: "fronteiras estão presentes fisicamente sempre que duas ou mais culturas se encontram, onde pessoas de diferentes raças ocupam o mesmo território, onde as elites e as classes populares se tocam, onde o espaço entre dois indivíduos se recolhe em intimidade."

Assim, elaboramos um programa de curso que foi dividido em três momentos. Primeiramente, discutiram-se autores dos estudos pós-coloniais, para colocar a própria ideia de nação em perspectiva histórica, evidenciando que a conquista dos povos não se deu apenas por meios físicos brutais, mas também pela violência simbólica e epistêmica, na qual o construto "língua" teve papel central. Depois, o curso abordou debates em antropologia linguística e linguística aplicada indisciplinar sobre questões de variação, comodificação e ideologias linguísticas. Aquela era uma turma de formando/as em letras que já haviam, em sua trajetória, participado de diferentes disciplinas no campo da linguística e da língua portuguesa. A proposta foi então desaprender (FABRÍCIO, 2006), isto é, questionar os regimes disciplinares de verdade que fundam a cultura monoglota da língua padrão. Desse modo, escutamos e dialogamos com diversas práticas linguísticas de fronteira (Português Índio, Língua de Sinais, produções periféricas como o hip-hop e o funk carioca). Finalmente, o curso promoveu um debate sobre a obra em portunhol de Fabian Severo, escritor e professor de Artigas, localizada na fronteira entre Uruguai e Brasil. 
A seguir, apresentaremos Fabian Severo e o encontro que tivemos com esse professor/escritor, bem como o impacto de sua obra em sala.

\section{FABIAN SEVERO: A CIRCULAÇÃO E AMPLIAÇÃO DAS FRONTEIRAS}

Em 2017, Fabian Severo ganha o prêmio nacional de literatura do Uruguai, com seu quarto livro escrito em portunhol, Viralata (SEVERO, 2015). Ainda que a sociedade do Uruguai também seja marcada por imaginações monolíngues, há uma grande valorização da fronteira na música e na literatura - não só do ponto de vista geográfico e sócio-histórico, mas também linguístico. Se nos documentos oficiais de escolarização do Uruguai há uma forte desvalorização de misturas linguísticas, mesmo em programas educacionais bilíngues ${ }^{2}$, há nas artes um tipo de licença poética em que o portunhol adquire grande valor. Como destaca Crinó (2016, p. 38), o portunhol é a forma translíngue capaz de "narrar a beleza e a unicidade do universo fronteiriço mas, ao mesmo tempo, denunciar as terríveis condições que o caracterizam." Severo, porém, desafia as "fronteiras da fronteira", isto é, as fronteiras que demarcam o que é permitido na arte mas vetado oficialmente nas escolas e círculos hegemônicos. Nascido numa fronteira atravessada por práticas linguísticas que desafiam a imaginação "uma língua-um povo-uma nação", Severo, além de escrever poesias e romances em portunhol, é professor de língua espanhola em Atlântida, situada a $45 \mathrm{~km}$ de Montevideo ${ }^{3}$. Ele também desenvolve trabalhos no Ministério da Educação do Uruguai. Foi a ocasião de seu trânsito quinzenal à capital do país que permitiu um encontro inesperado: na rodoviária, ele foi avistado por Adriana Lopes, que estava na cidade para apresentar, com Daniel Silva, uma comunicação sobre essa experiência translíngue no encontro da Associação LatinoAmericana de Sociologia (ALAS). Largando malas para trás, Adriana correu para falar com o poeta, que a acolheu com alegria. Campo fronteiriço, a rodoviária foi palco de um imprevisto que terminou se transformando em entrevista formal. Três dias depois, com a

\footnotetext{
${ }^{2}$ A homogenia linguística relacionada à identidade nacional do Uruguai está presente mesmo em programas bilíngues (português e espanhol), que adotam um entendimento do bilinguismo como "monolinguismos paralelos", ou seja, assumem a existência de duas línguas com fronteiras claras e com diferentes valores associados a elas (BORTOLINI; GARCEZ; SCHLATTER, 2013, p. 270).

${ }^{3} \mathrm{O}$ portunhol de fronteira falado e escrito por Fabian Severo difere do portunhol transidiomático. Como define Jacquemet (2016), "transidiomas são identificados em ambientes caracterizados pela co-presença de fala multilíngue e mídias digitais" (p.342). Assim, o portunhol transidiomático seriam aquelas práticas comunicativas produzidas pela combinação de pessoas, textos e tecnologias móveis, o que difere em alguma medida do portunhol praticado na fronteira do Brasil com países de língua oficial espanhola. Jacquemet acrescenta que a noção de transidioma permite "investigar as práticas comunicativas de grupos de pessoas, não mais territorialmente definidas, que usam uma gama de mídias face-a-face e à distância, assim combinando comunicação multimídia e multilíngue" (p. 341). Embora parcialmente distinto do transidioma, o portunhol de fronteira não é um fenômeno homogêneo: as práticas linguísticas da fronteira do Brasil com o Uruguai não produzem as mesmas formas híbridas que o portunhol falado noutras fronteiras. Nosso uso do termo 'portunhol' coincide com aquilo que foi descrito pelos linguistas uruguaios Elaizaincin, Behares e Barrios (1987) como Dialetos Portugueses del Urugay (DPU) e que posteriormente, em 2008, foi nomeado por pesquisadores daquele país como "português uruguaio", devido à conotação pejorativa que o termo "dialeto" carrega na linguagem ordinária (BORTOLINI; GARCEZ; SCHLATER, 2013). Mas não empregaremos essa designação porque os artistas de fronteira, como Fabian Severo, chamam de portunhol suas próprias práticas linguísticas.
} 
chegada de Daniel a Montevideo, nos reunimos com Fabian Severo no Palácio Brasil, para conversar sobre a experiência da fronteira Uruguai-Brasil e sobre o trabalho desenvolvido por Severo.

Naquela tarde, entre taças de vinho e xícaras de café, tematizamos um ofício comum a todos nós: a docência. Perguntamos sobre sua experiência como professor de língua, e Severo abordou esse ofício de uma forma extremamente política e solidária. Para além do ensino de língua entendido como estritamente linguístico, Fabian explicou que a sala de aula "é o lugar propício e genuíno, quase único, para habilitar o encontro entre as pessoas." Ele nos contou ainda que poucos contextos propiciam tantas horas juntas de convivência entre as pessoas, por tantos anos, como a escola: "é muito tempo, podendo se fazer muitos câmbios, pois é aí que se habilita o encontro." Para ele, encontros trazem novidades, surpresas e ações transformativas. Para Tsing (2016, p. 46), "[e]ncontros são, por sua própria natureza, indeterminados; somos transformados de uma forma imprevisível." Disse-nos o professor que, em suas aulas, mais do que aprender cânones literários, os/as estudantes são convidados a estabelecer encontros para conhecer o outro: "conhecer um outro ser, o que ele gosta, o que não gosta, o que o faz triste, como é sentar com outra pessoa, como é trabalhar em conjunto, como é estar um dia com dificuldades e outro dia estar bem de volta, como é ser solidário e colaborativo." Assim, aprender uma língua é aprender a ouvir histórias de outros e a contar sua própria história, "pois se uma história não é contada, ela não existe."

$\mathrm{Na}$ contramão dessa imaginação, Severo relata que, em sua formação como professor de língua materna, "aprendeu a corrigir toda a gente" e a entender a aula como o lugar da correção e da padronização linguísticas. Mas foi o reencontro com a experiência da fronteira, onde Severo aprendeu a falar e onde se dizem coisas misturadas [entreveradas], que permitiu que ele se dissesse: "quando eu senti uma necessidade de me dizer, não pude fazer em espanhol, no espanhol standard, esse invento, essa ficção chamada espanhol standard, não pude fazê-lo. Então eu queria dizer um montão de coisas que se passavam aí, mas não encontrava como. Até que um dia as palavras saíram todas misturadas [entreveradas]. E essa palavra era outra, era outra, era um verso, era um livro, era outro livro, era milhares de páginas, assim misturadas. Aí me dei conta de que estava na fronteira ou que estava em minha casa, era eu."

Foi exatamente por enunciar em sua obra uma disposição translíngue que privilegiamos, na terceira etapa da disciplina, o trabalho com a literatura de Severo e selecionamos um poema seu para a avaliação final do curso. Ler e ouvir esse poetaprofessor desafiavam imaginações acostumadas a avaliar tudo aquilo que se ouve e lê a partir da métrica padrão, da hierarquização e do apagamento: "como professor, tinha toda teoria [...] e aprendi a corrigir, [...] sabia corrigir minha mãe, minha avó, meus vizinhos". Segundo Severo, porém, essa disposição monolíngue terminou por restringir sua própria identidade: "isso fizeram comigo, me corrigiam, [me confinaram] a este cantinho, tentaram tirar todo meu acento." Este "cantinho" lembra um espaço de arestas bem definidas: fronteiras linguísticas que, nos termos de uma ideologia monoglota, seriam bem demarcáveis.

A questão que se pode depreender de sua literatura é que é possível desaprender essa ideologia monoglota: "o problema é que, quando a teoria não se adapta à realidade 
o que falha é a teoria, não é a realidade." Desconhecido pela turma, Fabian Severo embaralhava conceitos e trazia perplexidade à escuta. Que bonito e emocionante, mas que lingua é essa? Espanhol? Português? Espanhol estranho? Na aula de língua materna? Esses foram alguns dos comentários e perguntas levantados pela turma após assisti-lo declamar o poema Trinticuatro, juntamente com um outro artista de fronteira, Ernesto Días, em vídeo disponibilizado no Youtube. A seguir, transcrevemos o poema, que também está publicado em seu livro, Noite nu Norte (SEVERO, 2017, p. 58):

\footnotetext{
Mi madre hablaba muy bien, yo entendía.

Fabi andá faser los deber, yo hacía.

Fabi traseme meio litro de leite, yo traía.

Desí pra doña Cora que amañá le pago, yo decía.

Deya iso gurí y yo dejaba.

Pero mi maestra no entendía.

Mandaba cartas en mi cuaderno

todo con rojo (igualito a su cara) y firmaba abajo.
}

Mas mi madre no entendía.

Le iso pra mim, ijo y yo leía.

Mas mi madre no entendía.

Que fiseste meu fio, te dise que te portaras bien

y yo me portaba.

La historia se repitió por muchos meses.

Mi maestra escribía mas mi madre no entendía.

Mi maestra escribía mas mi madre no entendía.

Entonces cierto día mi madre entendió y dijo

Meu fío, tu terás que deiyá la iscuela

y yo dejé.

Escrito em portunhol, o poema aborda o problema do conflito entre duas ideologias de linguagem. A primeira, representada pela afinidade comunicativa entre o autor e sua mãe, sinaliza para a plasticidade de práticas linguísticas translíngues - tudo que a mãe ensinava Fabi aprendia. A segunda, representada pela visão normativa e monoglota de sua professora, aponta para o caráter institucional e avaliativo de comentários metapragmáticos orientados para o padrão - embora Fabi aparentemente tenha aprendido tudo o que a professora ensinava e escrevia, esta não entendia as formas translíngues do garoto (ou não queria entender, corrigindo-as de vermelho e assinando seu caderno, isto é, institucionalizando o poder da norma monoglota padrão). No poema, o conflito é também indexado como impossibilidade de mútuo entendimento: a mãe não entende a professora, e vice-versa. O garoto, no entanto, consegue habitar os dois mundos e, apesar de desempenhar bem as tarefas prescritas por ambas as ideologias, decide, após a ordem de sua mãe, abandonar o território monolíngue da escola. Metapragmaticamente, Fabi e 
sua mãe resistem e decidem abandonar os modos de pertencer prescritos pela ideologia monoglota padrão. Porém, tal ideologia não projeta apenas modos de falar e escrever prestigiados e corretos, mas também uma série de outros comportamentos que indiciam padrões de gênero, raça e classe (MILROY, 2011).

Mas, para além da interpretação que oferecemos deste poema, que série de efeitos ele produziu naquela turma de licenciatura em Nova Iguaçu?

\section{IDEOLOGIAS LINGUÍSTICAS EM AÇÃO}

O debate que sucedeu à prova abordando ideologias linguísticas e práticas translíngues no ensino de língua materna foi marcado pela invocação de diferentes ideologias sobre o funcionamento da linguagem, o que provocou, à medida que o diálogo transcorria, concordâncias e fricções diversas. Em sua formação no curso de letras do IM, esses/essas estudantes têm contato com professores de diferentes filiações nos estudos da linguagem - portanto, vozes de campos como sociolinguística, gramática normativa, gramática gerativa e sociologia da linguagem foram trazidas para o debate. Devido a essa formação heterogênea e às múltiplas leituras e histórias de vida das/dos estudantes, produziu-se, assim, um caleidoscópio de discursos metapragmáticos sobre linguagem. Por limitação de espaço, dividiremos a discussão sobre esse debate em três momentos.

Talvez a fricção mais significativa da discussão tenha sido aquela que ocorreu, já no início da aula, entre Luciana e Raquel. Adriana Lopes havia inicialmente pedido à turma que associasse sua reflexão sobre o poema - já realizada na prova - com a questão das ideologias linguísticas no ensino de língua materna e estrangeira. Luciana e Raquel produziram pontos de vista distintos sobre o conflito narrado no poema. Transcrevemos a seguir o debate entre as duas alunas:

Luciana - Então, quando eu peguei a prova em relação a nossa opinião e quando eu li o poema, achei interessante e só me fazia lembrar a questão da homogeneidade que não existe na língua e essa imposição de querer que nós falamos uma única língua, de a língua correta é a língua padrão, isso ficou martelando na minha cabeça o tempo inteiro. E eu acho que o poema trata disso, você não respeitar o mundo do aluno, a bagagem que ele traz. Daí me fez lembrar de Paulo Freire, né, sobre a questão do opressor. Então assim, só me remetia a esses assuntos, da imposição da gramática em achar assim ó: "Você só sabe FALAR, se você usar as normas padrões". Eu fiquei pensando nisso o tempo inteiro, todo o meu discurso ali foi a respeito disso. Eu acho que o texto, o poema, fala muito disso, dessa questão: da gente não entender, da gente não procurar entender que o outro FALA, o outro não faz nada agramatical na sua própria língua, ele tem a sua gramática internalizada, ele aprende, pode ser de uma forma diferente, mas é um aprendizado, é um falar próprio, e essa falta de respeito, essa falta de esforço da gente entender e aproveitar a linguagem para um processo de comunicação, eu achei interessante.

Raquel - Concordo, mas a forma (...) é um escolha puramente política, é um grupo que detém o poder. Se um grupo, se amanhã o grupo de, de, de domínio, o grupo de, de, de influência for o grupo que fala 'a gente vai'... a forma privilegiada vai passar a ser 'a gente vai', é simples. Para mim, o que cabe ao professor, e a gente tá neste curso e tem de pensar nisso: não é uma luta, não é combater, é trazer a luz, sabe? Trazer as duas formas e as duas formas existem, mostrar o que é uma forma adequada, só que é uma forma de poder e acabou. É um grupo social que está ali e não vai ter como lutar e acabar com isso. Se alguém tomar o poder entre aspas uma outra forma vai surgir como a forma mais privilegiada, ela sempre vai existir. 
Luciana - Aí eu sou obrigada a discordar de você ((risos na sala)) porque o 'a gente vai' ele não vai ser aceito em todo ambiente e esse pequeno grupo político social, e quanto mais eu leio o Bagno, mais eu entendo, porque a questão é mais social, o preconceito social é muito maior. O preconceito social, que é pra segregar, é pra separar mesmo, do que linguístico na realidade. Se aproveita da língua para se dar poder para quem já tem poder e a massa maior não consegue inverter isso. Ela tenta, mas ela não consegue. Você falou 'a gente vai, né?' 'A gente vai' até aceitam. Mas imagina a gente aqui, acadêmicos, que somos, aí chega uma pessoa aqui e fala assim 'a gente vamos ali?' Quem aqui não vai fazer assim: 'nossa fez a construção errada!' Quem aqui não vai fazer, de coração gente?! A gente faz. Eu lembro do meu primeiro seminário, eu falei assim: 'esse trem aqui, esse cara aqui'. Como eu fui recriminada por causa disso. Como assim você tá num ambiente acadêmico e tá falando 'este cara'! Lembra disso?

Raquel - não é nada disso. Não é só uma questão de uso privilegiado, aí é uma questão de adequação.

No primeiro turno de Luciana, o poema comparece como um texto que remete à dificuldade da escola em lidar com a heteroglossia constitutiva de toda prática linguística. Luciana sinaliza certa recusa existente ao trabalho com o conjunto múltiplo e heterogêneo de vozes e práticas linguísticas que compõem a vida social dos estudantes. Invocando os termos da pedagogia do oprimido, a estudante delineia visões de escola como o lugar da homogeneidade e da imposição de uma língua só, em que a diferença não é sequer ouvida. Nesse sentido, o poema leva a estudante a uma autocrítica, pois reconhece a predisposição (monoglota) "da gente não entender, da gente não procurar entender que o outro FALA." $\mathrm{Na}$ sequência, a estudante articula metadiscursos especializados - como a visão chomskyana de que não há desigualdade gramatical entre as línguas ou dialetos, já que estes partilham dos mesmos princípios; também a visão informacional do processo de comunicação, que comparece em Saussure e Jakobson, sugerindo certa igualdade na capacidade humana de representar - para justificar sua disposição translíngue, isto é, sua abertura ao fato de que "o outro não faz nada agramatical na sua própria língua (...) pode ser de uma forma diferente, mas é um aprendizado, é um falar próprio."

O posicionamento discordante de Raquel, que responde às disposições translíngues de Luciana, invoca tanto a tendência à naturalização da desigualdade linguística, um problema que temos sugerido ao longo deste artigo, quanto a tradição iluminista do ensino de língua no Brasil, delineada por Signorini (2004) em sua crítica aos discursos de ensinar língua como adequar. Embora Raquel aparentemente reconheça que a base da desigualdade linguística é política - "é uma escolha meramente política" -, sua racionalização sobre o problema da heterogeneidade situa o problema, de fato, no plano da natureza (isto é, do dado, do pressuposto, do não questionável). Certos índices de sua fala, como "é simples [a forma de prestígio] sempre vai existir", "[a hierarquização sempre existirá], pronto acabou", indicam que a desigualdade é inquestionável; em uma palavra, a diferença como desigualdade é um problema natural. Não é de estranhar que o papel do/a professor/a de língua, segundo Raquel, seja o de "esclarecer o ignorante em matéria de língua" (SIGNORINI, 2004): "não é uma luta, não é combater, é trazer a luz, sabe? O aparente pacifismo de seu discurso - "não é uma luta, não é combater [...] é mostrar o que é uma forma adequada" - é um eco de ideologias (linguísticas e sociais) de que a produção da desigualdade não é um problema político, mas sim natural - restandonos apenas "descrevê-lo". Nesse sentido, adequar-se é um outro nome para padronizarse. 
A fricção entre as duas alunas avança: nesse desdobrar do dissenso, Luciana vai crescentemente construindo o problema como sociopolítico - "quanto mais eu leio [Marcos] Bagno, mais eu entendo [que] a questão é mais social, o preconceito é mais social, [...] que é pra segregar, é pra separar mesmo, do que linguístico na realidade" - e reconhecendo que ele está inclusive na universidade - "como eu fui recriminada por [usar 'esse cara aqui']"; Raquel, por seu turno, reenquadra o debate nos termos da ideologia da "adequação" - que, como vimos, tem origem no iluminismo e escamoteia o campo social da distinção (BOURDIEU, 2008) e da legitimação dos privilégios de classe (PINTO, 2013).

O segundo momento acontece na sequência de uma intervenção de Adriana Lopes. As/os estudantes estavam discutindo o problema das coerções da escola para que se ensinem regras gramaticais nos moldes do ensino tradicional. A professora então intervém, perguntando por que ensinar nos termos da ideologia de língua como código fixo, se instituições como os PCNs e o ENEM têm projetado uma racionalização de língua como uso. Vejamos como sequencialmente Raquel, Adriana e Iris se posicionam no debate ideológico:

\footnotetext{
Raquel - Para mim não, para mim se é algo que é necessário, a sociedade precisa de pessoas que tenham o domínio da norma culta, então a escola tem de dar uma ferramenta para isso. É uma ferramenta. A pessoa vai utilizar no momento em que tem de ser utilizado.

Profa. Adriana - (...) Dominar a norma culta é dominar o que?

Raquel - é dominar as regras gramaticais

Profa. Adriana - e o que é dominar as regras gramaticais?

Flávia - é dominar isso que está inserido neste sistema

Profa. Adriana - que sistema?

Iris - esse sistema aristocrático, que você tem de ser aceito de alguma forma, e vc só é aceito quando você domina a língua do dominante, né?! Por exemplo, eu entendi o que a Mariana falou da comodidade porque como que é muito mais cômodo para você ensinar a língua do dominador, do que fazer esse aluno refletir do porquê ele precisa dessa língua do dominador e por que que a dele não é a certa. Se ele já passou por esse processo de naturalização da língua e já está dentro dele que o certo é e que para ele ser aceito neste sistema aristocrático ele precisa dominar a língua da classe dominante, então é isso. Então o professor produz esse fracasso escolar, o Bourdieu fala fracasso escolar, porque ele é fruto dessa aristocracia. E é difícil para o professor romper com isso.
}

Nesse trecho, ocorre uma mudança de enquadre sobre a ideia de 'sistema'. Raquel vinha defendendo uma ideologia utilitária de língua como código referencial variável, típica de estudos variacionistas que defendem a "adequação" linguística a domínios específicos; mas Adriana continuamente indaga Raquel sobre os termos dessa visão ideológica, até que Iris reenquadra a noção de sistema - de aparato referencial para mecanismo de diferenciação hierárquico ("sistema aristocrático").

Vejamos mais detalhadamente o posicionamento de Raquel. A racionalização de que o ensino de língua é um processo utilitário por meio do qual a aquisição de uma estrutura gramatical transparente, por si só, trará benefícios é uma ideologia linguística muito disseminada no contexto escolar. Esse tipo de justificação fundamenta, por exemplo, o argumento de Raquel sobre "a norma culta como ferramenta que a escola tem de dar”. Milroy (2011) e Silverstein (1996) argumentam que um dos elementos de 
ideologias monoglotas da língua padrão é a crença de que seu uso trará benefícios sociais e econômicos. Raquel reforça essa crença quando diz que "a sociedade precisa de pessoas que tenham o domínio da norma culta". Trata-se de uma imaginação típica de estados nacionais, mas que, obviamente, ganha contornos específicos de acordo com os contextos onde se materializa. Assim, no Brasil, a crença em um padrão benéfico está ligada a noções iluministas e modernistas normalmente encaixadas no conceito de norma cult $^{4}$. Em sua crítica a alguns trabalhos da sociolinguística brasileira que reificam uma norma/variedade culta como fenômeno linguístico estável, Pinto (2013) argumenta que essa delimitação é desenhada por critérios questionáveis. A fala que é ouvida, recortada e registrada como "culta" não tem essa característica intrínseca, mas é indexicalmente posicionada como tal, isto é, essa fala é o resultado de um movimento que cola aquilo que se concebe como norma culta à imagem do homem branco e europeu. Faraco (2002) destaca que está implícita nessa nomeação uma (des)classificação: a de que a grande maioria de brasileiras/os que não pertence a um elite seleta (que tem classe, raça, gênero e endereço certos) falaria uma "norma não culta, uma norma sem cultura".

Como forma de questionar essa imaginação, Adriana intervém e questiona o que seria "dominar a norma culta"; Raquel então reifica a coincidência 'culto-padrãogramática', até que Iris propõe uma mudança de enquadre, a partir da intervenção de Flávia, que traz a noção de sistema para o debate. Embora o turno de Flavia seja uma espécie de significante aberto, pois não especifica como 'sistema' está sendo posicionado, Íris intervém trazendo os termos de Bourdieu e da economia política da linguagem para o debate, qualificando o sistema como aristocrático. Iris defende que a padronização e/ou adequação são crenças acionadas por comodidade, ou seja, muitas vezes, é mais fácil para as/os professoras/es reproduzir mecanicamente certas crenças do que se levantar contra o que ela chama de "sistema aristocrático". Mencionando Bourdieu, Iris posiciona-se na contramão da crença sobre a benevolência do padrão, construída por Raquel. Para Iris não é (a falta de) língua culta a questão central do ensino, mas sim a falta de reflexão sobre esse processo, a naturalização da "língua do dominador como a língua certa" - o que também produziria o "fracasso escolar".

As falas de Iris e Flavia ampliaram o escopo do debate, criando uma equivalência entre sistema linguístico e sistema social. Assim, a padronização/adequação passou a ser tematizada não só como questão linguística, mas também social. Depois de mais essa fricção entre ideologias linguísticas, entremos no terceiro e último trecho em análise.

Eliseu - a gente vai ser professor e a gente tem de acreditar que estamos fazendo algo a mais do que trabalhar para as classes dominantes, para impor a norma padrão, só enfim, essa norma culta.

\footnotetext{
${ }^{4}$ Faraco (2002) faz uma distinção sobre a construção da norma padrão e da norma culta no Brasil, destacando que a última está relacionada aos usos linguísticos da elite escolarizada brasileira e a primeira se refere a "algo excessivamente artificial baseado em certo modelo lusitano de escrita, praticado por alguns escritores portugueses do Romantismo" (p. 43). Assim, para esse autor, um dos problemas linguísticos no Brasil é a não coincidência entre a norma culta e a norma padrão. Neste trabalho, compreendemos que qualquer padrão empírico é acompanhado de uma imaginação (ou ideologia) simultânea, de forma que qualquer delimitação sobre um padrão de língua será sempre uma forma de abstração. No caso brasileiro, ambas as normas, em diferentes medidas, são submetidas a um mercado linguístico de diferenciação, dentro do qual passam a indiciar ideologias linguísticas puristas e essencialistas.
} 
Luciana - Mas nós somos livres para decidir o que a gente faz com a língua?

Iris - nem com a língua, nem com as imagens. Por exemplo, se a gente for procurar um emprego a nossa aparência vai ter de mudar. Em tudo tem adequação. Então não é assim. Tudo eles te cobram, é um processo histórico que a Flavia falou. Então se você for conseguir um emprego, vai depender da sua cor de pele, sim; vai depender da cor do seu cabelo, sim. Em uma joalheria, tem loja que exige que a mulher pinte o cabelo de loiro. Então tem sim, pra poder trabalhar lá.

Profa. Adriana - e se ela falasse norma culta, mas não tivesse o cabelo loiro, conseguiria o emprego?

Iris - NÃO ((a turma ri em coro com a aluna))

Para nós, este é um momento importante, em que o problema da desigualdade linguística é deslocado do campo de uma referencialidade "apolítica" - suposta pelo debate de que falar adequadamente espelha uma variabilidade entendida como prévia e natural - para o terreno da indexicalidade (SIGNORINI, 2018). Sequencialmente, nos turnos acima, Eliseu argumenta que futuros/as professores de língua materna deveriam evitar "impor a língua padrão"; Fabiana então indaga se as/os usuárias/os da língua teriam liberdade de decidir o que fazer com a língua, parecendo implicar que não há outra escolha em matéria de ensino de língua do que ensinar a norma padrão. Íris concorda que não há muita escolha, mas sua resposta não reifica o problema da (falta de) escolha; ao contrário, a aluna correlaciona coerções no campo linguístico com coerções no campo imagético-corporal, apontando que formas linguísticas andam lado a lado com formas de pertencimento racial e social. A regulamentação do mercado, assim, não é só linguística, pois, para a estudante, "em tudo tem adequação", relacionando ideologias linguísticas com ideologias de gênero, de raça e de classe.

Deixando de lado a seriedade que até então dominava o debate, o riso coletivo em resposta à pergunta de Adriana sobre a norma culta ser suficiente (ou não) para que uma pessoa consiga um emprego quebra a seriedade, traz a ambiguidade e confessa o "racismo à brasileira" (PINHO, 2004) - um racismo sem objeto (ninguém é negro) e sem sujeito (ninguém é racista). Para Dahia (2007), é por meio do riso que a sociedade brasileira encontra uma via intermediária no cotidiano para extravasar esse racismo latente, sem assumir a posição de pessoa racista, menos ainda construir uma reflexão crítica sobre as questões que estão em pauta no debate. Assim, o riso coletivo coloca a turma nessa posição ambígua que, mesmo sem assumir, confessa: adequar-se à norma culta é para o mercado de trabalho (mas, para além dele) embranquecer-se. Dialogando com o crítico pós-colonial Franz Fanon (2008), poderíamos dizer que a imaginação sobre adequar-se formulada por Iris e reificada no riso coletivo revela que falar uma língua é mais do "que estar em condições de empregar certa sintaxe, possuir a morfologia de tal ou qual língua, mas é sobretudo assumir uma cultura, suportar o peso de uma civilização e [...] falar como um branco" (p. 36). 


\section{NOTAS PARA UMA PEDAGOGIA TRANSLÍNGUE}

Neste artigo, defendemos que o ensino de língua portuguesa é uma ação política. Em diálogo com os debates sobre ideologias linguísticas, apontamos que as crenças sobre linguagem e ensino são uma ação interessada (portanto, política). No campo do ensino de língua materna no Brasil, embora tenham ocorrido nos últimos vinte anos avanços nos currículos de ensino de língua, em que as teorias linguísticas tiveram um contribuição fundamental, a desconstrução do próprio objeto língua (associado a um poder/saber colonialista e monoglota) não chegou efetivamente nos currículos. Um indício disso é que consideramos tímido o debate sobre ideologias linguísticas na reflexão sobre ensino de língua e formação de professores no Brasil.

A despeito da timidez de um debate dessa natureza, abordamos uma experiência de ensino translíngue que planejamos numa universidade pública, em que colocamos em diálogo ideologias linguísticas de línguas como caleidoscópios (CAVALCANTI; MAHER, 2018) - portanto compostas de múltiplas camadas, conflitos e contradições - e a produção translinguística de Fabian Severo, que se abre à diferença no ensino e na forma de encarar os usos a língua. Nos excertos de interação analisados, que decalcamos da última aula do curso, vê-se que habitar essa abertura à diferença ocorreu lado a lado com o dissenso, o conflito e a contradição. Esperamos que a pedagogia translíngue, a exemplo do posicionamento linguístico-ideológico de Fabian Severo, sirva como metáfora para pensar o ensino como abertura à diferença. Uma metáfora que desestabiliza as naturalizações linguísticas suscitadas e problematizadas em uma sala a partir do poema Trinticuatro - uma crônica poética que a mãe de Fabi diz para o filho "deiyá la iscuela", um ato que não é solitário, tampouco é de responsabilidade exclusiva do estudante e de seu pertencimento. Assim como Fabi, muitas/os jovens, por não se padronizarem ou não se adequarem a certos padrões (que não são unicamente linguísticos), são, de fato, expulsas/os de instituições escolares. Longe de ser uma fórmula, a pedagogia translíngue é uma prática utópica ${ }^{5}$ de resistência à homogeneização e à exclusão de estudantes não padronizados; é uma direção para a diferença que, no limite, pode significar não só uma abertura para a alteridade, mas a possibilidade, como no caso de Fabian (e de outras/os estudantes e futuras/os professoras/es), de transformação do próprio "eu", constituído na fronteira.

\section{REFERÊNCIAS}

ANZALDUA, G. Borderlands/ La Frontera: The New Mestiza. San Francisco: Aunt Lute Books, 1987. ARENDT, H. A Condição Humana. Rio de Janeiro: Forense, 1991

\footnotetext{
5 Aqui lembramos de Eduardo Galeano (1993) citando Fernando Birri, cineasta argelino, que utilizava imagens fílmicas como utopias. Também uruguaio, Galeano diz que a utopia não é 'isso ou aquilo', mas é algo que está lá, no horizonte. Nas palavras de Galeano, "Me acerco dos pasos, ella se aleja dos pasos. Camino diez pasos y el horizonte se corre diez pasos más allá. Por mucho que yo camine, nunca la alcanzaré. ¿Para qué sirve la utopía? Para eso sirve: para caminhar” (p. 230). Assim, a pedagogia translíngue é esse caminhar utópico em direção ao outro, em direção à transformação.
} 
AZEVEDO, P. Tornar-se professor de história: a escrita monográfica de conclusão de curso na formação de professor(a)/autor(a) no curso de licenciatura PARFOR/UFRRJ. In: SIMPÓSIO NACIONAL DE HISTÓRIA - CONTRA OS PRECONCEITOS: HISTÓRIA E DEMOCRACIA. 29., 2017, Brasília. Anais... Brasília: UnB, 2017. Disponível em: <http://www.snh2017.anpuh.org/site/anais $\geq$

BAUMAN, R.; BRIGGS, C. Poetics and performance as critical perspectives on language and social life. Annual Review of Anthropology, v. 19, p. 59-88, 1990.

BLOMMAERT, J. The Sociolinguistics of Globalization. Cambridge: Cambridge University Press, 2010.

BORTOLINI, L.; GARCEZ, P; SCHLATTER, M. Práticas linguísticas e identidades em trânsito: espanhol e português em um cotidiano comunitário escolar uruguaio na fronteira com o Brasil. In: MOITA LOPES, L. P. (Org.) Português no século XXI: ideologias linguísticas. São Paulo: Parábola, 2013. p. 249-273.

BORTONI-RICARDO, S. The Urbanization of Rural Dialect Speakers: a sociolinguistic study in Brazil. Cambridge: Cambridge University Press, 1985.

BOURDIEU, P. A distinção: crítica social do julgamento. São Paulo: Edusp; Porto Alegre: Zouk, 2008.

BRASIL. Parâmetros Curriculares Nacionais - Pluralidade cultural e orientação sexual; Temas Transversais. Brasília: MEC, 1997.

BUNZEN, C. A fabricação da disciplina escolar Português. Revista Diálogo Educacional, v. 11, n. 34, p. 885-911, set./dez. 2011.

CAVALCANTI, M. Estudos sobre educação bilingue e escolarização em contextos de minorias lingüísticas no Brasil. D.E.L.T.A., v. 15, p. 385-418, 1999.

CAVALCANTI, M.; MAHER, T. M. (Org.) Multilingual Brazil: language resources, identities and ideologies in a globalized world. New York: Routledge, 2018.

CÉSAR, A. L. ; CAVALCANTI, M. Do singular para o multifacetado: O conceito de língua como caleidoscópio. In: CAVALCANTI, M. C., BORTONI-RICARDO, S.M. (Org.). Transculturalidade, linguagem e educação. Campinas: Mercado de Letras, 2007. p. 45-66.

CRINO, C. Portunhol/Portuñol na poesia de Fabián Severo. Revista Interfaces, v. 24, n. 1, p. 35-53, 2016.

DAHIA, S. A mediação do riso na expressão e consolidação do riso no racismo no Brasil. Sociedade $e$ Estado, v. 23, n. 3, p. 697-720, 2008.

ELIZAICIN, A; BEHARES, L.E; BARRIOS, G. Nós falemo brasileiro: dialectos portugueses del Uruguay. Montevideo: AMERSUR, 1987.

FABRÍCIO, B. Linguística aplicada como espaço de desaprendizagem: redescrições em curso. In: MOITA LOPES, L. P. (Org.). Por uma Linguística Aplicada Indisciplinar. São Paulo: Parábola, 2006, p. 45-65.

FABRÍCIO, B.; BORBA, R. Remembering in order to forget: scaled memories of slavery in the linguistic landscape of Rio de Janeiro. In: BLACWOOD, R.; MACALISTER, J. (Org.). Multilingual memories: memory, monuments and the linguistic landscape. London: Bloomsbury. No prelo.

FANON, F. Pele negra, máscaras brancas. Salvador: EDUFBA, 2008.

FARACO, C. A. Norma-padrão brasileira. Desembaraçando alguns nós. In: BAGNO, M. (Org.). Linguística da norma. São Paulo: Loyola, 2002, p. 37-61.

FREITAS, H. C. L. Formação de professores no Brasil: 10 anos de embate entre projetos de formação. Educação \& Sociedade, v. 23, n. 80, p. 137-168, 2002.

GALEANO, E. Las palabras andantes. Buenos Aires: Catálogos S.R.L, 1993.

GERALDI, J. W.; SILVA, L.; FIAD, R. Lingüística, ensino de língua materna e formação de professores. D.E.L.T.A., v. 12, n. 2, p. 307-326, 1996.

GERALDI, J.W. et al. (Org.). O texto na sala de aula. São Paulo: Ática, 2002.

HORNER, B.; MIN-ZHAN, L; ROYSTER, J.; TRIMBUR, J. Language Difference in Writing: Toward a Translingual Approach. College English, v. 73, n. 3, p. 303-321, 2011.

HOUAISS, A. Dicionário Houaiss da Língua Portuguesa. São Paulo: Objetiva, 2001.

IRVINE J.; GAL, S. Language ideology and linguistic differentiation. In: KROSKRITY, P. (Org.). Regimes of Language: Ideologies, polities, and identities. Santa Fe: American Research Press, 2000. p. 35-84.

JACQUEMET, M. Language in the Age of Globalization. In: BONVILLAIN, N. (Org.) The Routledge Handbook of Linguistic Anthropology. London: Taylor and Francis, 2016. p. 329-347.

LOPES, Adriana Carvalho; SILVA, Daniel do Nascimento e. Todos nós semos de frontera: ideologias linguísticas e a construção de uma pedagogia translíngue. Linguagem em (Dis)curso - LemD, Tubarão, SC, v. 18, n. 3, p. 695-713, set./dez. 2018. 
LEE, J.; JENKS, C. Doing translingual dispositions. College Composition and Communication, v. 68, n. 2, p. 317-344, 2016.

MAHER, T. M.; CAVALCANTI, M. C. Interação transcultural na formação do professor índio. In: SEKI, L. (Org.). Lingüística indígena e educação na América Latina. Campinas: Editora da Unicamp, 1993. p. 217-230.

MILROY, J. Ideologias linguísticas e as consequências das padronizações. In: LAGARES, X; BAGNO, M. Políticas da norma e conflitos linguísticos. São Paulo: Parábola, 2011, p. 49-89.

MOITA LOPES, L. P. "Ideologia Linguística: como construir discursivamente o português no século XXI. In: MOITA LOPES, L. P (Org.). O português no século XXI. Cenário geopolítico e sociolinguístico. São Paulo: Parábola Editorial, 2013. p. 18-52.

PINHO, O. O efeito do sexo: políticas de raça, gênero e miscigenação. Cadernos Pagu, n. 23, p. 89-119, 2004.

PINTO, J. P. Prefigurações identitárias e hierarquias linguísticas na invenção do português. In: MOITA LOPES, L. P. (Org.) Português no século XXI: ideologias linguísticas. São Paulo: Parábola Editorial, 2013. p. 120-143.

SEVERO, F. Viralata. Montevideo: Rumbo Editorial, 2015.

Noite nu Norte: Versión anoitesida. Montevideo: Kapparazón Ediciones, 2017.

SIGNORINI, I. Por uma teoria da desregulamentação lingüística. In: BAGNO, M. (Org.). A linguística da norma. São Paulo: Loyola, 2002. p. 93-125.

Invertendo a lógica do projeto escolar de esclarecer o ignorante em matéria de língua. Scripta, v. 7, n.14, 2004, p. 90-106, 2004.

Metapragmáticas da redação científica de "alto impacto". Revista do GEL, v. 14, p. 59-85, 2018.

SILVA, D. N. A Propósito da Linguística Aplicada 30 anos depois: quatro truísmos correntes e quatro desafios. D.E.L.T.A., n. 31 - Especial, p. 340-376, 2015.

SILVERSTEIN, M. Language structure and linguistic ideology. In: CLYNE, P.; HANKS, W.; HOFBAUER, C. (Org.). The elements: a parasession on linguistic units and levels. Chicago: Chicago Linguistic Society, 1979. p.193-247.

Monoglot 'standard' in America: Standardization and metaphors of linguistic hegemony. In: BRENNEIS, D.; MACAULAY, R. The matrix of language. Boulder: Westview, 1996, p. 284-306. SOARES, M. Português na Escola: História de uma disciplina curricular In: BAGNO, M. (Org.) Linguística da norma. São Paulo: Loyola, 2002, p. 155-177.

SUASSUNA, L. O que são, como e por que se escreveram os parâmetros curriculares nacionais de língua portuguesa - o professor como leitor de propostas oficiais de ensino. In: MARINHO, M.; SILVA, C. (Org.). Leituras do professor. Campinas: Mercado de Letras, 1998. p. 175-184.

TSING, A. The mushroom at the end of the world. Princeton: Princeton University Press, 2012.

Recebido em: 06/07/18. Aprovado em: 24/09/18.

Title: Todos nós semos de frontera: Linguistic ideologies and the production of a transligual pedagogy

Authors: Adriana Carvalho Lopes; Daniel do Nascimento e Silva

Abstract: This paper attempts to dislocate the debate on Portuguese language teaching away from nature and towards politics. Thereunto, it argues that to think of linguistic ideologies, understood as lay and specialized rationalizations about language form and function is equivalent to embedding teaching in politics, inasmuch as these ideologies are invested with the political interests of the groups holding them. Empirically, the paper questions the monolingual ideologies informing the Parâmetros Curriculares Nacionais, or the federal curricula guidelines, and other discourses about the nation. It contrasts these ideologies with Fabian Severo's poetry in Spanguese and his rationalizations. The paper also gauges attachments and frictions in the context of language-ideological discussions of students who participated in a trans-lingual proposal of Portuguese language teaching.

Keywords: Trans-lingual Pedagogy. Spanguese. Language Ideologies.

LOPES, Adriana Carvalho; SILVA, Daniel do Nascimento e. Todos nós semos de frontera: ideologias linguísticas e a construção de uma pedagogia translíngue. Linguagem em (Dis)curso - LemD, Tubarão, SC, v. 18, n. 3, p. 695-713, set./dez. 2018. 
Título: Todos nós semos de frontera: ideologías linguísticas y la construcción de una pedagogía translengua

Autores: Adriana Carvalho Lopes; Daniel do Nascimento e Silva

Resumen: Este artículo busca desplazar el debate sobre la enseñanza de lengua portuguesa del campo de la naturaleza y traerla para el campo de la política. Para ello, propone que problematizar ideologías lingüísticas, entendidas como racionalizaciones de aquellos que desconocen y especializadas sobre la forma y la función del lenguaje, equivale a politizar la enseñanza, en la medida en que esas ideologías son investidas de intereses políticos de los grupos que las sostienen. Empíricamente, el artículo cuestiona las ideologías monolingües que basan los Parâmetros Curriculares Nacionais y otros discursos sobre la nación, contrastándolas con la producción poética y las racionalizaciones de Fabian Severo, poeta uruguayo y profesor que escribe en portuñol. El texto aún explora alineamientos y fricciones entre ideologías lingüísticas entre estudiantes que participaron de una propuesta translengua de enseñanza de lengua madre.

Palabras clave: Pedagogía translengua. Portuñol. Ideologías lingüísticas.

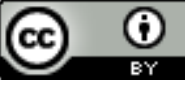

Este texto está licenciado com uma Licença Creative Commons Atribuição 4.0 Internacional. 